\title{
Level of Perceived Stigma Among Caregivers of Persons with Severe Mental IIIness in Jimma City, Ethiopia: A Cross-sectional Study
}

\author{
Muhammed Seid Muhammed ${ }^{1, *}$, Markos Tesfaye ${ }^{2}$, Eshetu Girma $^{3}$, Mengesha Birkie ${ }^{1}$ \\ ${ }^{1}$ Department of Psychiatry, Wollo University, Dessie, Ethiopia \\ ${ }^{2}$ Department of Psychiatry, Research Directorate, St. Paul's Hospital Millennium Medical College, Addis Ababa, Ethiopia \\ ${ }^{3}$ Department of Health Education and Behavioral Sciences, Addis Ababa University, Addis Ababa, Ethiopia \\ Email address: \\ wusmndahn2008@gmail.com (M. S. Muhammed), tesmarkos@yahoo.com (M. Tesfaye), grmsht@yahoo.com (E. Girma), \\ mengeshasun@gmail.com (M. Birkie) \\ ${ }^{*}$ Corresponding author
}

\section{To cite this article:}

Muhammed Seid Muhammed, Markos Tesfaye, Eshetu Girma, Mengesha Birkie. Level of Perceived Stigma Among Caregivers of Persons with Severe Mental Illness in Jimma City, Ethiopia: A Cross-sectional Study. American Journal of Clinical and Experimental Medicine. Vol. 9, No. 4, 2021, pp. 77-85. doi: 10.11648/j.ajcem.20210904.11

Received: April 12, 2021; Accepted: July 9, 2021; Published: July 22, 2021

\begin{abstract}
Background: Stigma associated with mental illness is a psychosocial consequence that causes indescribable suffering for the victim. Therefore this study aimed to assess the magnitude and factors associated with level of perceived stigma among caregivers of persons with severe mental illness in Jimma city, Ethiopia. Methods: A cross-sectional study was conducted with a face-to-face interview from September 20 to October 20/2012 G.C. Family interview schedule was used to assess perceived stigma. A total of 289 participants were recruited using a consecutive sampling technique. Data were analyzed using SPSS version 16 software. Results: The most frequently endorsed item was having felt grief or depression because of having a mentally ill family member or relative (96.5\%). The mean stigma score was $17.8 \pm 6.9$ and the majority of the respondents (54.7\%) had a high stigma score. Caregivers/Family members who were spouse to the patient (AOR=4.25, 95\%CI: $1.12-16.13$ ) and longer duration of illness ( $\mathrm{AOR}=3.60,95 \% \mathrm{CI}$ : $1.42-9.44)$ were associated with higher stigma. But a person with mental illness who had verbal/physical violent behavior towards caregivers/family members and other people at the time of the illness (AOR $=0.34,95 \%$ CI: $0.17-0.70$ ) and among those family members who attributed the cause of mental illness as the loss of properties and unsuccessful life ( $\mathrm{AOR}=0.27,95 \% \mathrm{CI}$ : $0.08-0.89$ ) at $\mathrm{p}=0.032$. Were associated with low stigma respectively. Conclusions: Perceived stigma was found to be a common problem among caregivers of persons with severe mental illness. Becoming spouse of the person, duration of illness, patient with violent behavior and, those caregivers who attributed the cause of mental illness as the loss of properties and unsuccessful life were significantly associated with perceived stigma.
\end{abstract}

Keywords: Severe Mental Illness, Perceived Stigma, Caregivers, Jimma, Ethiopia

\section{Introduction}

The term stigma was defined as "something that detracts from the character or reputation of a person, group, etc.; a mark of disgrace or reproach; a mark, sign, etc indicating that something is not considered normal [1]. It is also defined in terms of undesirable, "deeply discrediting" attributes that "disqualify one from full social acceptance" and motivate efforts by the stigmatized individual to hide the mark when possible [2]. Health-related stigma is a social process or related personal experience characterized by exclusion, rejection, blame, or devaluation that results from experience or reasonable anticipation of an adverse social judgment about a person or group identified with a particular health problem [3]. Goffman states that it is not only stigmatized people who suffer from the social implications of stigma but also the people who are associated with them in some way. For example persons with mental health problems, as well as 
people associated with them. He called this stigma by association, "courtesy stigma" [2]. In this study, the definition of Perceived stigma was adopted as families/caregivers of persons with severe mental illness perceived that society excludes, reject, blame or devaluate them because they are associated with stigmatized group, mentally ill individual. They fear or perceive to be present in the community or society [4].

In both low- and high-income countries, there is a long history of people with mental illness being stigmatized along with their families [5]. Family members are often the primary caregivers of people with mental illness. They provide psychological and physical support and often have to accept the financial expenses associated with mental health treatment and care. In addition to the obvious distress from seeing a loved one being disabled by the consequences of mental illness, family members are also exposed to the stigma and discrimination associated with mental illness. Rejection by friends, relatives, neighbors, and the community as a whole can increase the family's sense of isolation, resulting in restricted social activities, and the denial of equal participation in normal social networks [5].

Regardless of its causes, stigma towards mental illness has been found to pose a major barrier to some of the most basic tasks of life, such as establishing and maintaining friendships, employment, housing, marital and relationship problems as well as increased risk of disability and advanced disease and poorer treatment prognosis in most conditions [6, 7]. The perception to be rejected in the community makes life even more difficult for the caregivers and families of people with serious mental illness.

The development and implementation of effective interventions to create more supportive and understanding communities would be a challenging and worthwhile endeavor [8]. Current researches indicated that public perceptions of family stigma negatively impacts family members, which in turn, negatively impacts their relatives with mental illness [9]. Perceived stigma may affect the lives of the people concerned in the same way as an experienced stigma. It also may cause the same negative effects on public health programs as experienced stigma [6].

In Ethiopia, little is known about the extent of stigma on families/caregivers of persons with severe mental illness. However, indirect evidence shows that misconceptions about mental illness exist in the community. For example, a study was done on a community sample living in rural town southwestern Ethiopia found that less educated people have negative attitudes on the marital prospects and work opportunity of schizophrenia and illiterate people have a more negative attitude towards living with persons with epilepsy and schizophrenia in the same house [10]. Therefore, this study aimed to assess the magnitude and to identify factors associated with perceived stigma among caregivers of persons with severe mental illness in Jimma city, Ethiopia.

\section{Materials and Methods}

\subsection{Study Setting and Sample}

The study was conducted at Jimma city, located in the southwestern part of Ethiopia, from September 20 to October 20/2012. Jimma city is located $354 \mathrm{kms}$ South West of Addis Ababa and has a total area of 46.23 square kilometers. It has four health centers and one general hospital. The city has also one teaching hospital which is providing inpatient and outpatient mental health services for approximately 126 new and 874 follow-up outpatients per month.

The cross-sectional study design was used to conduct this study on 289 family members/caregivers of persons with severe mental illness by using consecutive sampling techniques. The study population for this study was a sample of family members/caregivers of persons with severe mental illness living in Jimma city who came to Jimma University specialized hospital (JUSH) psychiatry clinic.

The sample size was calculated by using the single population proportion formula by considering the prevalence of perceived or experienced family stigma to be $75 \%$ from a previous study conducted in Butajira, Ethiopia in 200[11]. A structured questionnaire was first developed in English and translated to Amharic and Afan Oromo then back-translated independently into English to check for consistency and semantic validity.

\subsection{Measurements}

The family member/caregivers of a person with severe mental illness were interviewed by psychiatry nurses using the Family interview schedule (FIS) instrument which was developed as part of a WHO study on the course and outcome of schizophrenia and special attention were given to the stigma section [12]. This instrument (the stigma part) was used in Butajira, Ethiopia to assess the perceived stigma of family members of schizophrenia and affective disorders [11], the perception of stigma in people with epilepsy and their relatives [13], and also in Madras, India [14]. The whole instrument was used and translated into many different languages in the world [12].

Reliability test: In this study, the internal consistency of the Amharic version of Family Interview Schedule, stigma part, was found to be Cronbach's Alpha $=0.78$, and based on the standard items it was 0.771 which indicates that the scale was respectable and acceptable to the study participants. The stigma part has 14 items and a four-point Likert scale from "not at all" rated 0 , "sometimes" rated 1 , "often" rated 2 to "a lot" rated 3, concerning stigma. To assess the distribution of stigma responses between groups, a stigma sum score was computed by summarizing all positive responses $(>0)$ and a high stigma score was considered as above the meanwhile low stigma score considered as a score below the mean. In this study, severe mental illness (SMI) was operationalized as a clinical diagnosis from patients' charts that includes psychotic disorder or a severe mood disorder (schizophrenia, schizophreniform, schizoaffective, bipolar disorder, and 
major depressive disorder).

\subsection{Data Analysis}

Data were entered into a computer using SPSS version-16 for analysis. The presence and degree of association between perceived stigma and the respondents' socio-demographic features and other variables were investigated by binary logistic regression and finally all independent variables whose $p$-value $\leq 0.25$ were entered in multivariate analysis to identify independently associated factors for perceived stigma. A p-value $<0.05$ was considered statically significant.

\section{Results}

\subsection{Socio-demographic Character}

A total of 289 caregivers were interviewed. Among all, the majority $148(52.2 \%)$ were females, 125 (43.3\%) were Oromo by ethnicity and $123(42.6 \%)$ were followers of the Islamic religion. The mean age of the family members/caregivers was $39.7 \pm 12.7$ years. The median family monthly income of respondents was 1000.00 \pm 929.13 Ethiopian Birr.

Out of the total respondents, the majority $105(36.3 \%)$ were siblings to the patients followed by 103 (35.6\%) parents and the majority $176(60.9 \%)$ of the family members/caregivers were living together with the patient in the same house. Among those who were living together with the patient, $107(60.8 \%)$ were living together for more than 20 years (Table 1$)$.

Table 1. Socio-demographic characteristics of the families of the persons with severe mental illness in Jimma city, $2012(n=289)$.

\begin{tabular}{|c|c|c|c|}
\hline \multicolumn{2}{|c|}{ Socio-demographic Characteristics } & \multirow{2}{*}{$\begin{array}{l}\text { Number } \\
141\end{array}$} & \multirow{2}{*}{$\begin{array}{l}\text { Percent } \\
48.8\end{array}$} \\
\hline \multirow{2}{*}{ Sex } & Male & & \\
\hline & Female & 148 & 51.2 \\
\hline \multirow{4}{*}{ Age in year } & $<30$ & 65 & 22.5 \\
\hline & $30-40$ & 96 & 33.2 \\
\hline & $41-50$ & 55 & 19.0 \\
\hline & $\geq 51$ & 73 & 25.3 \\
\hline \multirow[t]{2}{*}{ Religion } & Muslim & 123 & 42.6 \\
\hline & Orthodox & 111 & 38.4 \\
\hline \multirow{5}{*}{ Ethnicity } & Protestant & 50 & 17.3 \\
\hline & Others* & 5 & 1.7 \\
\hline & Oromo & 125 & 43.3 \\
\hline & Amhara & 61 & 21.1 \\
\hline & Dawuro & 29 & 10.0 \\
\hline \multirow{5}{*}{ Marital status } & Gurage & 18 & 6.2 \\
\hline & Others** & 56 & 19.4 \\
\hline & Married & 160 & 55.4 \\
\hline & Single & 63 & 21.8 \\
\hline & Divorced & 35 & 12.1 \\
\hline \multirow{3}{*}{ Education al level } & Widowed & 31 & 10.7 \\
\hline & Illiterate & 25 & 8.7 \\
\hline & $1-8$ & 92 & 31.8 \\
\hline \multirow{5}{*}{ Work status } & $9-12$ & 118 & 40.8 \\
\hline & $>12$ & 54 & 18.7 \\
\hline & Unemployed & 20 & 6.9 \\
\hline & Employed & 205 & 71.0 \\
\hline & Others & 64 & 22.1 \\
\hline
\end{tabular}

\subsection{Patient Characteristics and Illness Condition}

Regarding the persons with severe mental illness, the majority $173(59.9 \%)$ were males, and their age was ranged from 18-80 years with a mean of $32.9 \pm 12.7$ years. The majority of patient's diagnosis 120 (41.5\%) was schizophrenia as shown in Table 2. For the majority 206 $(71.3 \%)$ of the patients, the onset of the illness was between 15 and 34 years of age. The median age of onset of illness was $24.0 \pm 12.2$ years. Regarding the duration of the illness, the majority of the patients $168(58.1 \%)$ had less than 5 years The range of the duration of illness was 4 months to 43 years and the median year of the duration of illness was $5.0 \pm 5.2$ years. The majority of the patients $152(52.6 \%)$ had no history of hospital admission and among those who had admission, 71 (51.8\%) were admitted two times and above.

The majority of the respondents $238(82.4 \%)$ had no family members with a mental illness other than the current patient. A high proportion of the patients $199(69.0 \%)$ had verbal/physical violent behavior towards their family members/caregivers or other people at the time of their illness but only 90 (31.0\%) had no verbal/physical violent behavior at all.

According to the family members/caregivers report, 85 (29.4\%) of patients were drinking alcohol. Among those who drank alcohol, 53 (62.4\%) were drunk daily and 126 (43.6\%) were chewed khat. Of those patients who chewed khat, 99 $(78.6 \%)$ chewed daily. The majority of the patients 189 (65.4\%) were able to accomplish their daily activities during the time of data collection (Table 2).

Table 2. Socio-demographic characters and illness conditions of the persons with severe mental illness in Jimma city, 2012 ( $n=289)$.

\begin{tabular}{llll}
\hline Variables & & Number & Percent \\
\hline Sex & Male & 173 & 59.9 \\
& Female & 116 & 40.1 \\
Age group in year & $<25$ & 77 & 26.7 \\
& $25-34$ & 113 & 39.2 \\
& $35-44$ & 46 & 15.9 \\
& $\geq 45$ & 53 & 18.3 \\
Age of onset of illness (in a year) & $<15$ & 21 & 7.3 \\
& $15-24$ & 133 & 46.0 \\
& $25-34$ & 73 & 25.3 \\
& $\geq 35$ & 62 & 21.4 \\
Diagnosis & Schizophrenia & 120 & 41.5 \\
& Bipolar disorder & 63 & 21.8 \\
& Major depression & 93 & 32.2 \\
& Other & 13 & 4.5 \\
Duration of illness (in a year) & $<5$ yr & 168 & 68.1 \\
& $6-10$ yr & 80 & 27.7 \\
& $>10$ yr & 41 & 14.2 \\
History of admission & No & 152 & 52.6 \\
Family history of mental illness & Yes & 137 & 47.4 \\
& No & 238 & 82.4 \\
& Yes & 51 & 17.6 \\
\hline
\end{tabular}

\subsection{Perceived Stigma of Caregivers of a Person with Severe Mental Illness}

When at least one positive response to the items was regarded as having perceived some sort of stigma, all respondents had more than one positive answer giving $100 \%$ 
perceived stigma by the caregivers.

The mean stigma score of the responses to stigma items was $17.80 \pm 6.95$ and the minimum and maximum scores were 2 and 32 respectively for the total positive answers. For analysis purposes, the stigma score was dichotomized into high stigma, above the mean, and low stigma, below the mean. Based on this category, the majority of the respondents $158(54.7 \%)$ had a high stigma score. Concerning the specific items, the most frequently endorsed item 279 (96.5\%) was felt grief or depression because of the presence of a mentally ill person in the family followed by $252(87.2 \%)$ explaining to others that the patient isn't like their picture of "crazy" people. The third frequently endorsed item $225(77.8 \%)$ was helping other people to understand what it is like to have a family member with a psychiatric problem. The least frequently endorsed item $118(40.8 \%)$ was to feel that somehow it might be your fault as shown in (Table 3 ).

Table 3. Stigma items were presented to family members and the corresponding responses in Jimma city, 2012 ( $n=289)$.

\begin{tabular}{|c|c|c|c|c|c|}
\hline Items & $\mathbf{0}$ & 1 & 2 & 3 & positive answer \\
\hline Worried about being treated differently & 97 & 107 & 71 & 14 & $192(66.4 \%)$ \\
\hline Worried people would know out about it & 82 & 105 & 90 & 12 & $207(71.6 \%)$ \\
\hline Felt the need to hide this fact & 95 & 66 & 110 & 18 & $194(67.1 \%)$ \\
\hline Helping other people to understand what it is like to have a family member with a psychiatric problem & 64 & 135 & 78 & 12 & $225(77.8 \%)$ \\
\hline Making an effort to keep this fact a secret & 83 & 50 & 118 & 38 & $206(71.3 \%)$ \\
\hline Worried about being avoided & 110 & 89 & 76 & 14 & $179(61.9 \%)$ \\
\hline Worried that people would blame you for his/her problems & 162 & 42 & 69 & 16 & $127(43.9 \%)$ \\
\hline Worried that a person looking to marry would be reluctant to marry into your family & 84 & 29 & 109 & 67 & $205(70.9 \%)$ \\
\hline Worried about taking him or her out & 78 & 123 & 74 & 14 & $211(73.0 \%)$ \\
\hline Felt ashamed or embarrassed about it & 90 & 18 & 66 & 115 & $199(68.8 \%)$ \\
\hline Sought out people who also have a family member who has had a psychiatric problem & 118 & 78 & 63 & 30 & $171(59.1 \%)$ \\
\hline Felt grief or depression because of it & 10 & 23 & 53 & 203 & $279(96.5 \%)$ \\
\hline Felt that somehow it might be your fault & 171 & 29 & 64 & 25 & $118(40.8 \%)$ \\
\hline
\end{tabular}

Not at all (0), Sometimes (1), Often (2), A lot (3).

Table 4. The proportion of stigma category with socio-demographic and other variables of the respondents in Jimma city, $2012(n=289)$.

\begin{tabular}{|c|c|c|c|}
\hline Variables & $\mathbf{N}$ & Low stigma & High stigma \\
\hline \multicolumn{4}{|l|}{ Sex of family } \\
\hline Male & 141 & $58(41.1 \%)$ & $83(58.9 \%)$ \\
\hline Female & 148 & $73(49.3 \%)$ & $75(50.7 \%)$ \\
\hline \multicolumn{4}{|c|}{ Age of the family in years } \\
\hline$<30$ & 65 & $32(49.2 \%)$ & $33(50.8 \%)$ \\
\hline $30-40$ & 96 & $48(50.0 \%)$ & $48(50.0 \%)$ \\
\hline $41-50$ & 55 & $15(27.3 \%)$ & $40(72.7 \%)$ \\
\hline$\geq 51$ & 73 & $36(49.3 \%)$ & $37(50.7 \%)$ \\
\hline \multicolumn{4}{|l|}{ Marital status } \\
\hline Married & 160 & $72(45.0 \%)$ & $88(55.0 \%)$ \\
\hline Single & 63 & $30(47.6 \%)$ & $33(52.4 \%)$ \\
\hline Divorced & 35 & $16(45.7 \%)$ & $19(54.3 \%)$ \\
\hline Widowed & 31 & $13(41.9 \%)$ & $18(58.1 \%)$ \\
\hline \multicolumn{4}{|l|}{ Educational status } \\
\hline Illiterate & 25 & $10(40.0 \%)$ & $15(60.0 \%)$ \\
\hline $1-8$ & 92 & $47(51.1 \%)$ & $45(48.9 \%)$ \\
\hline $9-12$ & 118 & $52(44.1 \%)$ & $66(55.9 \%)$ \\
\hline College/University & 54 & $22(40.7 \%)$ & $32(59.3 \%)$ \\
\hline \multicolumn{4}{|l|}{ Work status } \\
\hline Unemployed & 20 & $11(55.0 \%)$ & $9(45.0 \%)$ \\
\hline Employed & 205 & $82(40.0 \%)$ & $123(60.0 \%)$ \\
\hline Others & 64 & $38(59.4 \%)$ & $26(40.6 \%)$ \\
\hline \multicolumn{4}{|c|}{ Relation to the patient } \\
\hline Parents & 103 & $48(46.6 \%)$ & $55(53.4 \%)$ \\
\hline Siblings & 105 & $50(47.6 \%)$ & $55(52.4 \%)$ \\
\hline Child & 28 & $9(32.1 \%)$ & $19(67.9 \%)$ \\
\hline Spouse & 26 & $8(30.8 \%)$ & $18(69.2 \%)$ \\
\hline Other & 27 & $16(59.3 \%)$ & $11(40.7 \%)$ \\
\hline
\end{tabular}

Living together with family

\begin{tabular}{|c|c|c|c|}
\hline No & 113 & $50(44.2 \%)$ & $63(55.8 \%)$ \\
\hline Yes & 176 & $81(46.0 \%)$ & $95(54.0 \%)$ \\
\hline \multicolumn{4}{|l|}{ Sex of the patient } \\
\hline Male & 173 & $80(46.2 \%)$ & $93(53.8 \%)$ \\
\hline Female & 116 & $51(44.0 \%)$ & $65(56.0 \%)$ \\
\hline \multicolumn{4}{|c|}{ Age of the patient in a year } \\
\hline$<25$ & 77 & $34(44.2 \%)$ & $43(55.8 \%)$ \\
\hline $25-34$ & 113 & $50(44.2 \%)$ & $63(55.8 \%)$ \\
\hline $35-44$ & 46 & $24(52.2 \%)$ & $22(47.8 \%)$ \\
\hline$\geq 45$ & 53 & $23(43.4 \%)$ & $30(56.6 \%)$ \\
\hline \multicolumn{4}{|c|}{ Age of onset of the illness } \\
\hline$<15 \mathrm{yr}$ & 21 & $13(61.9 \%)$ & $8(38.1 \%)$ \\
\hline $15-24 \mathrm{yr}$ & 133 & $60(45.1 \%)$ & $73(54.9 \%)$ \\
\hline $25-34 \mathrm{yr}$ & 73 & $32(43.8 \%)$ & $41(56.2 \%)$ \\
\hline$\geq 35 \mathrm{yr}$ & 62 & $26(41.9 \%)$ & $36(58.1 \%)$ \\
\hline \multicolumn{4}{|l|}{ Diagnosis } \\
\hline Schizophrenia & 120 & $63(52.5 \%)$ & $57(47.5 \%)$ \\
\hline Bipolar disorder & 63 & $24(38.1 \%)$ & $39(61.9 \%)$ \\
\hline Major depression & 93 & $34(36.6 \%)$ & $59(63.4 \%)$ \\
\hline Others & 13 & $10(76.9 \%)$ & $3(23.1 \%)$ \\
\hline \multicolumn{4}{|c|}{ Duration of the illness } \\
\hline$<5 \mathrm{yr}$ & 168 & $68(40.5 \%)$ & $100(59.5 \%)$ \\
\hline $6-10 \mathrm{yr}$ & 80 & $33(41.2 \%)$ & $47(58.8 \%)$ \\
\hline$>10 \mathrm{yr}$ & 41 & $30(73.2 \%)$ & $11(26.8 \%)$ \\
\hline \multicolumn{4}{|c|}{ History of admission } \\
\hline No & 152 & $77(50.7 \%)$ & $75(49.3 \%)$ \\
\hline Yes & 137 & $54(39.4 \%)$ & $83(60.6 \%)$ \\
\hline \multicolumn{4}{|l|}{ Daily activity } \\
\hline No & 100 & $53(53.0 \%)$ & $47(47.0 \%)$ \\
\hline Yes & 189 & $78(41.3 \%)$ & $111(58.7 \%)$ \\
\hline
\end{tabular}

In the descriptive analysis, the majority of male respondents $83(58.9 \%)$ had a high stigma score; and more 
than half of those family members/caregivers 40 (72.7\%) whose ages were between 41 to 50 years were found to have high stigma score. Regarding educational status, $60 \%$ of the illiterate and $59.3 \%$ of those educated colleges and above had a high stigma score. When it was compared by employment status, the majority $(60 \%)$ of the employed had a high stigma score as compared to unemployed (45.0\%). Majority of the respondent who was a child to the patient $(67.9 \%)$ had high stigma score next to spouses $(69.2 \%)$. As the age of onset of the illness increases their high stigma score percentage increases (Table 4).

Regarding responses to the attribution of causes of mental illness, $16.3 \%$ of the respondents attributed mental illness to substance abuse followed by loss of properties and unsuccessful life $(15.9 \%)$, and grief from the loved one $(14.2 \%)$.

Various coping mechanisms were also suggested to deal with the illness difficulties; the majority (75.7\%) was suggested by "went to health professional" followed by "went to holy water" (36.3\%)

\subsection{Factors Associated with Perceived Stigma}

In the bivariate logistic regression analysis, family/caregiver perceived stigma was significantly associated with age (41-50 years) and work status (other=student, housewife \& daily labor) of the family members of persons with severe mental illness at p-value $\leq$ 0.05 . It was also significantly associated with the diagnosis of the patient (major depressive disorders), duration of illness ( $<10$ years), and those patients who had verbal/physical violent behavior towards family members and other people at the time of their illnesses at $p$-value $\leq 0.05$. Multiple logistic regressions were performed including all variables with a $\mathrm{p}$ value $\leq$ of 0.25 in the bivariate logistic regression to increase our confidence of having adequately controlled for confounding variables. Only variables with a p-value lower than 0.05 remained in the final model and were taken as statistically significant (Table 5).

After multivariate analyses were computed, family perceived stigma was significantly associated with relationship to the patient (spouse), duration of the illness ( $<10$ years), and the patient's behavior (verbally/physically violent towards family members and other people at the time of the illness). The odds of the perceived stigma of the spouse of the patient were 4.25 times higher than those of the parents of the patient $(\mathrm{AOR}=4.25,95 \% \mathrm{CI}: 1.12-16.13)$ at $\mathrm{p}=0.034$.

The odds of the perceived stigma of the family members/caregivers of the patient who had less than 5 years duration of illness were 3.60 times higher than from those family members of a patient who had greater than 10 years duration of illness $(\mathrm{AOR}=3.60,95 \% \mathrm{CI}$ : $1.42-9.44)$ at $\mathrm{p}=0.009$; and those family members/caregivers of a patient who had 6-10 years duration of illness had also more perceived stigma than from those family members/caregivers of a patient who had greater than 10 years duration of illness. The odds of perceived stigma were more than 3 times higher when the patients' duration of illness was 6-10 years (AOR=3.44, 95\% $\mathrm{CI}: 1.31-9.07)$ at $\mathrm{p}=0.012$.

Those family members/caregivers of persons with mental illness who had verbal/physical violent behavior towards family members and other people had a less perceived stigma.

The odds of reporting perceived stigma were 0.34 times less when the patient was verbally/physically violent towards family members and other people at the time of the illness $(\mathrm{AOR}=0.34,95 \% \mathrm{CI}: 0.17-0.70)$ at $\mathrm{p}=0.004$. Age of the family members, work status, and diagnosis of persons with mental illness were confounding variables (Table 5).

Table 5. Associated factors for the perceived stigma of families of persons with severe mental illness in Jimma city, 2012 ( $n=289)$.

\begin{tabular}{|c|c|c|c|c|}
\hline & & $\operatorname{COR}(95 \% \mathrm{CI})$ & AOR (95\%CI) & p-value \\
\hline \multicolumn{5}{|l|}{ Sex of family } \\
\hline Male & 141 & $1.393(0.875-2.218)$ & $1.155(0.657-2.030)$ & 0.616 \\
\hline Female & 148 & 1.00 & 1.00 & \\
\hline \multicolumn{5}{|l|}{ Age of family } \\
\hline$<30 \mathrm{yr}$ & 65 & $1.003(0.514-1.958)$ & $0.700(0.249-1.967)$ & 0.498 \\
\hline $30-40 \mathrm{yr}$ & 96 & $0.973(0.529-1.788)$ & $0.632(0.263-1.518)$ & 0.305 \\
\hline $41-50 \mathrm{yr}$ & 55 & $2.595(1.225-5.493)$ & $2.051(0.833-5.049)$ & 0.118 \\
\hline \multicolumn{5}{|l|}{ Ethnicity } \\
\hline Oromo & 125 & 1.00 & 1.00 & \\
\hline Dawuro & 29 & $1.754(0.755-4.072)$ & $1.369(0.525-3.571)$ & 0.521 \\
\hline Amhara & 61 & $1.423(0.764-2.651)$ & $1.342(0.645-2.792)$ & 0.431 \\
\hline Guragie & 18 & $1.451(0.528-3.985)$ & $1.520(0.463-4.988)$ & 0.490 \\
\hline Others & 56 & $0.800(0.425-1.504)$ & $0.608(0.289-1.281)$ & 0.191 \\
\hline \multicolumn{5}{|l|}{ Work status } \\
\hline Others & 64 & $0.456(0.258-0.808)$ & $0.526(0.265-1.046)$ & 0.067 \\
\hline \multicolumn{5}{|c|}{ Relation to the patient } \\
\hline Parents & 103 & 1.00 & 1.00 & \\
\hline Siblings & 105 & $0.960(0.557-1.655)$ & $1.235(0.518-2.944)$ & 0.634 \\
\hline Child & 28 & $1.842(0.762-4.453)$ & $3.740(0.835-16.758)$ & 0.085 \\
\hline Spouse & 26 & 1.964 (0.784- 4.919) & $4.249(1.119-16.136)$ & $0.034 *$ \\
\hline Other & 27 & $0.600(0.254-1.418)$ & $0.807(0.253-2.578)$ & 0.718 \\
\hline
\end{tabular}




\begin{tabular}{|c|c|c|c|c|}
\hline & & $\operatorname{COR}(95 \% \mathrm{CI})$ & AOR (95\%CI) & p-value \\
\hline \multicolumn{5}{|l|}{ Diagnosis } \\
\hline Schizophrenia & 120 & 1.00 & 1.00 & \\
\hline Bipolar disorder & 63 & $1.796(0.964-3.346)$ & $1.482(0.713-3.082)$ & 0.292 \\
\hline Major depression & 93 & $1.918(1.103-3.336)$ & $1.183(0.575-2.437)$ & 0.648 \\
\hline Others & 13 & $0.332(0.087-1.265)$ & $0.307(0.061-1.538)$ & 0.151 \\
\hline \multicolumn{5}{|l|}{ Age onset of illness } \\
\hline$<15 \mathrm{yr}$ & 21 & $0.506(0.197-1.301)$ & $1.643(0.468-5.769)$ & 0.438 \\
\hline $15-24 \mathrm{yr}$ & 133 & 1.00 & 1.00 & \\
\hline $25-34 \mathrm{yr}$ & 73 & $1.053(0.593-1.871)$ & $1.031(0.507-2.097)$ & 0.933 \\
\hline$\geq 35 \mathrm{yr}$ & 62 & $1.138(0.619-2.093)$ & $0.840(0.311-2.273)$ & 0.732 \\
\hline \multicolumn{5}{|l|}{ Duration of illness } \\
\hline$<5 \mathrm{yr}$ & 168 & $4.011(1.882-8.545)$ & $3.603(1.382-9.394)$ & $0.009^{*}$ \\
\hline $6-10 \mathrm{yr}$ & 80 & $3.884(1.708-8.835)$ & $3.440(1.305-9.071)$ & $0.012 *$ \\
\hline$>10 \mathrm{yr}$ & 41 & 1.00 & 1.00 & \\
\hline \multicolumn{5}{|l|}{ History of admission } \\
\hline No & 152 & 1.00 & 1.00 & \\
\hline Yes & 137 & $1.578(0.989-2.518)$ & $1.634(0.913-2.925)$ & 0.098 \\
\hline \multicolumn{5}{|l|}{ Violent behavior } \\
\hline No & 90 & 1.00 & & \\
\hline Towards family only & 95 & $1.196(0.657-2.175)$ & $0.835(0.410-1.699)$ & 0.558 \\
\hline Towards other only & 1 & 0.000 & 0.000 & 1.00 \\
\hline Towards both & 103 & $0.421(0.236-0.751)$ & $0.342(0.166-0.704)$ & $0.004 *$ \\
\hline
\end{tabular}

NB: - * p- value $<0.05$ is considered as significant

Multiple logistic regressions were also performed for responses to the attribution of causes of mental illness. Among those family members who attributed the cause of mental illness as the loss of properties and unsuccessful life were less stigmatized than those who did not attribute $(\mathrm{AOR}=0.27$, 95\%CI: 0.08-0.89) at $\mathrm{p}=0.032$. Those family members who attributed the cause of mental illness as other medical illness like head trauma, tuberculosis, injuries, and participating in the battle were less stigmatized than those family members who did not attribute $(\mathrm{AOR}=0.24,95 \% \mathrm{CI}$ : $0.07-0.81$ ) at $\mathrm{p}=0.021$ (Table 6).

Table 6. Attributions of causes of mental illness by the family of persons with severe mental illness in Jimma city, 2012 ( $n=289$ ).

\begin{tabular}{|c|c|c|c|c|c|}
\hline Causes & & $\mathbf{N}$ & P-value & AOR & $95 \%$ CI. \\
\hline \multirow[t]{2}{*}{ Heredity } & No & 284 & & 1.00 & \\
\hline & Yes & 5 & 0.132 & 0.195 & $0.023-1.639$ \\
\hline \multirow[t]{2}{*}{ Supernatural force } & No & 280 & & 1.00 & \\
\hline & Yes & 9 & 0.285 & 0.396 & $0.072-2.162$ \\
\hline \multirow[t]{2}{*}{ Thinking over } & No & 277 & & 1.00 & \\
\hline & Yes & 12 & 0.282 & 0.410 & $0.081-2.083$ \\
\hline \multirow[t]{2}{*}{ Addiction } & No & 242 & & 1.00 & \\
\hline & Yes & 47 & 0.061 & 0.317 & $0.095-1.055$ \\
\hline \multirow[t]{2}{*}{ Annoyed } & No & 253 & & 1.00 & \\
\hline & Yes & 36 & 0.198 & 0.499 & $0.173-1.438$ \\
\hline \multirow[t]{2}{*}{ Grief } & No & 248 & & 1.00 & \\
\hline & Yes & 41 & 0.509 & 0.651 & $0.183-2.322$ \\
\hline \multirow[t]{2}{*}{ Love } & No & 271 & & 1.00 & \\
\hline & Yes & 18 & 0.748 & 1.263 & $0.304-5.240$ \\
\hline Loss \& unsuccessfulness & Yes & 46 & $0.032 *$ & 0.267 & $0.080-0.891$ \\
\hline \multirow[t]{2}{*}{ Evil eye, magic \&devil } & No & 266 & & 1.00 & \\
\hline & Yes & 23 & 0.304 & 0.496 & $0.130-1.892$ \\
\hline \multirow[t]{2}{*}{ Others } & No & 219 & & 1.00 & \\
\hline & Yes & 70 & $0.021 *$ & 0.241 & 0.071-0.810 \\
\hline
\end{tabular}

$N B$ : - * P- value $<0.05$ is considered as significant

\section{Discussion}

The results of this particular study showed that nearly all family members expressed their concern about stigma despite they were from a different socio-demographic group and having relatives with different mental illnesses. In this study, conducted in Jimma city health institution, perceived stigma among families/ caregivers of persons with severe mental illness was high which is supported by the study done in rural Ethiopia, Butajira there was more perceived stigma among family members of persons with schizophrenia and major affective disorders in the urban residents than in the rural [11]. 
The findings in this study are consistent with the findings of other studies which report the existence of clear evidence of stigma among family members of patients with severe mental illnesses [11, 14-18]. However, how the respondents experience stigma might be different from our study, because of the differences in the culture, setting, and other factors.

The mean stigma score was $17.80 \pm 6.95$ and the majority of the respondents had a high stigma score above the mean $(54.7 \%)$; which is also consistent with the study done in India [14] (mean stigma score was 18.84 \pm 3.69 ), and Butajira, Ethiopia [11].

The most frequently endorsed item from the 14 stigma items was felt grief or depression because of the presence of a mentally ill person in the family $(96.5 \%)$, which is similar to the study done in India [14] using the same instrument on the primary caregiver of a person with schizophrenia (80\%), and the second most frequently endorsed item in this study was explaining to others that the patient is not "crazy" $(87.2 \%)$ whereas it was the least endorsed item in India (16\%); this differences could be due to socio-cultural difference and the caregivers of persons with different diagnoses in this study. Family members/caregivers worried about being treated differently by neighbors was $66.4 \%$ which is higher than from the study done in Butajira (42.1\%), India (37\%), and in Morocco (41\%) [11, 16, 18]; the difference might be due to sampling size difference in addition to the above-mentioned differences. Two third of the family members felt the need to hide their relatives' mental illness which is also higher when compared to the study done in India [13] and Butajira [11]; these could be the study participant differences. The study was done in the U.S.A. [17] showed that about half of the family members reported concealing the hospitalization of their mentally ill relative at least to some degree which was in agreement with this study, history of admission was associated with high stigma in bivariate logistic regression analysis even though it was not in the final model.

In multivariate logistic regression analysis the independently associated factors of perceived stigma were spouses as family members/caregivers, duration of the illness ( $<10$ years), and verbally/physically violent behavior of the patient towards family members and other people at the time of their illness. Those family members/caregivers who were spouse had more than 4 times higher perceived stigma than those family members/caregivers who were parents to the patient but the study was done in the U.S.A. which included only parents and spouses of the recently hospitalized patients, spouses were twice as likely to report avoidance by others as parents at the $p<0.10$ level [17]. This difference could be due to the instrument used to assess stigma difference (only avoidance and concealment in the U.S.A.).

Regarding the duration of the illness, if the patients' duration of illness was less than 10 years, the family members had nearly 3.5 times higher perceived stigma than those family members of patients whose duration of illness was greater than 10 years. This was consistent with the study done in India (short duration of illness) [14]. This was also consistent with the study done in Calgary, a higher level of distress among newer caregivers of schizophrenia [19], and the study was done in China (range from 1.5-4.3 years) even though it was said long duration [16], it was a short duration when compared to this study. In another study in New York City on stigma in families of individuals in early stages of psychotic illness, associative stigma was endorsed more by family members of patients with recentonset psychosis than by family members of prodromal individuals [20].

On the other hand, the duration of illness greater than 10 years was associated with a low perceived stigma might be due to the family members may adopt the illness and develop coping mechanisms.

Regarding patients' violent behavior, those family members or verbally/physically violent patients towards family members and other people at the time of the illness were less stigmatized than those family members of nonviolent patients at all. This is somewhat consistent with the study done in the U.S.A in which concealment by family members was higher among patients with less severe positive symptoms (hostility) at baseline [17]. It seems an unexpected finding but it might be due to the family members might not spend time worrying that people know about it if the patient was verbally/physically violent; no need of effort to hide and secrete the illness rather want help from others. On the other hand, if the patient had no violent behavior, the family members spent more time worrying that people may know about the illness and effort to keep secrete and try to hide the illness.

Although not statically significant, the majority of male respondents $(58.9 \%)$ had a high stigma score; and more than two-third $(72.7 \%)$ of those family members whose age were between 41 to 50 years were found to have high stigma score. Being male gender for family members/caregivers had more stigma might be due to having more responsibility to the mentally ill relatives, taking them to health institutions, covering the cost of treatment, and have been more contact to other people as an employee and for many issues than the female family members in this country context. This might make them vulnerable to develop fear and worry about being avoided by friends and coworkers.

Regarding responses to attribution of causes of mental illness, the majority $(16.3 \%)$ of the respondents attributed mental illness to substance abuse followed by loss of properties and unsuccessful life $(15.9 \%)$. which is inconsistent with the study done in India [14]; could be due to socio-cultural and diagnosis differences. In a community study in the Butajira area, the majority $(27 \%)$ of the respondents attributed to supernatural forces [11], but in this study supernatural force was attributed by only $3.1 \%$ which might be due to knowledge differences among respondents in the two studies since this study was conducted at the hospital, the respondents might get psycho-education about the causes of mental illness.

In general, our findings suggest that stigma is a concern and a problem for families/caregivers of persons with severe 
mental illness. The family perceived stigma made a double burden for them in addition to giving care for their mentally ill relatives; especially for Ethiopian families/caregivers who are the primarily responsible body to give care for their ill relatives including taking them to health institutions and providing medication at home.

The result has also great social implications in that the stigma might restrict the families/caregivers to involve in many social activities, in which many days to day activities are directly related to social gatherings in Ethiopia as well in the study area. Stigma can be a major obstacle to treatment delay, recovery and can limit opportunities of work and social functioning of both persons with mental health problems and their family members/caregivers.

\section{Conclusion}

Perceived stigma was found to be a common problem among caregivers of persons with severe mental illness. Becoming spouse of the patient, duration of illness, patient with violent behavior and, those caregivers who attributed the cause of mental illness as the loss of properties and unsuccessful life were significantly associated with perceived stigma. Hence, counseling and acceptance to the concern of care giver about stigma and set strategies for the prevention of stigma helps them to cope with rejection by others.

\section{Lists of Abbreviations / Acronyms}

AOR: Adjusted Odds Ratio

SMI: Severe Mental Illness

WHO: World Health Organization

SPSS: Statistical Package for the Social Sciences

FIS: Family interview schedule

U.S.A: United States of America

\section{Declaration}

\section{Ethical Approval and Consent to Participants}

Ethical clearance was obtained from the ethical committee of Jimma University College of public health and medical sciences. An official letter of co-operation was also written to Jimma city administration offices and specifically to the city health office. Verbal informed consent was obtained from each respondent. Individuals who do not volunteer to continue from the beginning or any part of the interview have respected the right to do so.

\section{Consent for Publication}

Not applicable.

\section{Availability of Data and Material}

The data was available when it is requested.

\section{Competing Interests}

The authors declare that they have no competing interests.

\section{Authors' Contributions}

MS was the only author involved in proposal development, conducting the analysis, and writing the manuscript. The second, third involved advising the principal author in proposal development and analysis of data. The fourth author contributed to writing, editing the manuscript and process the publication. All authors read and approved the final manuscript.

\section{Acknowledgements}

We want to give special thanks to Jimma University Department of Psychiatry, Jimma University specialized hospital, the data collectors, supervisors, and respondents for their cooperation and contribution.

\section{References}

[1] Benson P. Ethnocentrism and the English dictionary: Routledge; 2002.

[2] Goffman E. Stigma: Notes on the management of spoiled identity: Penguin books; 1974.

[3] Weiss MG, Ramakrishna J. Stigma interventions and research for international health. The Lancet. 2006; 367 (9509): 536-8.

[4] LeBel TP. Perceptions of and responses to stigma. Sociology Compass. 2008; 2 (2): 409-32.

[5] Organization WH. Investing in mental health. 2003.

[6] Van Brakel W. Measuring health-related stigma-A literature review. Report. Amsterdam: Royal Tropical Institute; 2005.

[7] Nicholls P, Wiens C, Smith W. Delay in the presentation in the context of local knowledge and attitude towards leprosythe results of qualitative fieldwork in Paraguay. International Journal of Leprosy and Other Mycobacterial Diseases. 2003; 71 (3): 198-209.

[8] Struening EL, Perlick DA, Link BG, Hellman F, Herman D, Sirey JA. Stigma as a barrier to recovery: The extent to which caregivers believe most people devalue consumers and their families. Psychiatric services. 2001; 52 (12): 1633-8.

[9] Larson JE, Corrigan P. The stigma of families with mental illness. Academic Psychiatry. 2008; 32 (2): 87-91.

[10] Amare D. Awareness and attitude towards common mental health problems, Agaro town, South Western Ethiopia. Ethiopian journal of health sciences. 2005; 15: 1-19.

[11] Shibre T, Negash A, Kullgren G, Kebede D, Alem A, Fekadu $A$, et al. Perception of stigma among family members of individuals with schizophrenia and major affective disorders in rural Ethiopia. Social Psychiatry and Psychiatric Epidemiology. 2001; 36 (6): 299-303. 
[12] Sartorius N, Janca A. Psychiatric assessment instruments developed by the World Health Organization. Social Psychiatry and Psychiatric Epidemiology. 1996; 31 (2): 55-69.

[13] Shibre T, Alem A, Tekle-Haimanot R, Medhin G. Perception of stigma in people with epilepsy and their relatives in Butajira, Ethiopia. Ethiopian Journal of Health Development. 2006; 20 (3).

[14] Thara R, Srinivasan T. How stigmatizing is schizophrenia in India? International Journal of Social Psychiatry. 2000; 46 (2): 135-41.

[15] Östman M, Kjellin L. Stigma by association: psychological factors in relatives of people with mental illness. The British Journal of Psychiatry. 2002; 181 (6): 494-8.

[16] Phillips MR, Pearson V, Li F, Xu M, Yang L. Stigma and expressed emotion: a study of people with schizophrenia and their family members in China. The British Journal of Psychiatry. 2002; 181 (6): 488-93.

[17] Phelan JC, Bromet EJ, Link BG. Psychiatric illness and family stigma. Schizophrenia bulletin. 1998; 24 (1): 115-26.

[18] Kadri N, Manoudi F, Berrada S, Moussaoui D. Stigma impact on Moroccan families of patients with schizophrenia. The Canadian Journal of Psychiatry. 2004; 49 (9): 625-9.

[19] Martens L, Addington J. The psychological well-being of family members of individuals with schizophrenia. Social Psychiatry and Psychiatric Epidemiology. 2001; 36 (3): 12833.

[20] Wong C, Davidson L, Anglin D, Link B, Gerson R, Malaspina $\mathrm{D}$, et al. Stigma in families of individuals in the early stages of psychotic illness: family stigma and early psychosis. Early Intervention in Psychiatry. 2009; 3 (2): 108-15. 